\title{
Effect of Tai Chi exercise on older people with nephritis
}

\author{
Cao Yun ${ }^{1}$ and Niu Aijun ${ }^{2 *}$ \\ ${ }^{1}$ Department of Sport of Zunyi Normal University, Zunyi, Guizhou 563002, China. \\ ${ }^{2}$ Wushu Department, Guangzhou Sport Universtiy, Guangzhou 510500, China.
}

Accepted 19 April, 2011

\begin{abstract}
To evaluate the effect of Tai Chi exercise on older people with nephritis, 124 older people with nephritis were asked to practice Tai Chi exercise for $\mathbf{4 0}$ min once every day. Results showed that Tai Chi" quan exercise significantly decrease high-shear whole blood viscosity, low-shear whole blood viscosity, plasma viscosity, erythrocyte sedimentation rate (ESR), hematocrit (HCT), usea nitrogen, creatinine and creatinine scavenging rate during 12 months of practice. This indicates that Tai Chi exercise is beneficial to prevent and delay nephritis deterioration.
\end{abstract}

Key words: Tai Chi, nephritis, old people, hematocrit (HCT).

\section{INTRODUCTION}

Tai Chi (TC) is a traditional Chinese martial art that has been demonstrated by numerous studies to improve the ability to balance on one leg (Bohannon et al., 1984; Iverson et al., 1990; Schaller, 1996; Hong et al., 2000; Jonsson et al., 2004). The movements engage continuous body and trunk rotation, flexion/extension of the hips and knees, postural alignment, and the coordination of the arms (Swaim, 1999). Five major ancient Tai Chi styles are currently practiced: Chen, Yang, Sun, Wu (Jian Qian), and Wu (He Qin) styles. Each style has a distinctive protocol that differs from the other styles in the postures or forms included, the order in which they appear, the pace at which movements are executed, and the level of difficulty (Yang, 1991).

Nephritis refers to inflammation of one or both kidneys. It can be caused by infection, but is most commonly caused by autoimmune disorders that affect the major organs. For example, those with lupus are at a much higher risk for developing nephritis. In rare cases nephritis can be genetically inherited, though it may not present in childhood (Yang et al., 2000; Nkeh-Chungag et al., 2009).

Nephritis is a serious medical condition which is the ninth highest cause of human death. As the kidneys inflame, they begin to excrete needed protein from the body into the urine stream. This condition is called proteinuria. Loss of necessary protein due to nephritis

\footnotetext{
${ }^{*}$ Corresponding author. E-mail: niuajgzu1@sina.cn
}

can result in several life-threatening symptoms. Most dangerous in cases of nephritis is the loss of protein that keeps blood from clotting. This can result in blood clots causing sudden stroke (Dooley and Falk, 2007; Morteza et al., 2010; Lamb et al., 2003).

\section{METHODS}

\section{Participants}

The participants were recruited from Guangzhou City, China. The sample was composed of 124 older people ( 73 women and 51 men; mean age of $68.2 \pm 6.82$ years). The participants were asked to practice Tai Chi quan for 40 min once every day. The study lasted for 12 months. Some biochemical indexes were measured at 3 month intervals. All indexes were measured using a auto hemorheological analyzers.

\section{Statistics}

All data are presented as means \pm SE. The results were calculated statistically using 1-way analysis of variance (ANOVA) and the Duncan multiple range test. Differences were considered to be significant at $\mathrm{P}<0.05$ (Snedecor and Cochran, 1989).

\section{RESULTS AND DISCUSSION}

Nephritis is an inflammation of the kidney and is categorised into Glomerulonephritis (inflammation of the glomeruli, when the term 'nephritis' is used without further qualification, this is often the condition meant), Interstitial 
Table 1. Tai Chi quan affecting high-shear whole blood viscosity, low-shear whole blood viscosity, plasma viscosity, erythrocyte sedimentation rate (ESR), and hematocrit (HCT).

\begin{tabular}{cccccc}
\hline Time & $\begin{array}{c}\text { High-shear whole } \\
\text { blood viscosity (mPa-s) }\end{array}$ & $\begin{array}{c}\text { Low-shear whole blood } \\
\text { viscosity }(\mathbf{m P a} \cdot \mathbf{s})\end{array}$ & $\begin{array}{c}\text { Plasma viscosity } \\
(\mathbf{m P a} \cdot \mathbf{s})\end{array}$ & $\begin{array}{c}\text { Erythrocyte sedimentation } \\
\text { rate (ESR) }(\mathbf{m m} / \mathbf{h})\end{array}$ & $\begin{array}{c}\text { Hematocrit } \\
(\mathbf{H C T})(\%)\end{array}$ \\
\hline 0 & $5.97 \pm 0.42$ & $13.52 \pm 1.73$ & $2.91 \pm 0.08$ & $29.77 \pm 10.53$ & $59.68 \pm 4.71$ \\
3 & $5.68 \pm 0.65$ & $13.06 \pm 1.72$ & $2.63 \pm 0.09$ & $27.89 \pm 8.15$ & $56.72 \pm 3.94$ \\
6 & $5.32 \pm 0.42$ & $12.95 \pm 1.07$ & $2.43 \pm 0.08$ & $27.02 \pm 9.56$ & $55.38 \pm 4.08$ \\
9 & $5.14 \pm 0.49$ & $12.78 \pm 1.35$ & $2.26 \pm 0.09$ & $25.48 \pm 6.35$ & $54.96 \pm 3.78$ \\
12 & $5.01 \pm 0.38$ & $12.67 \pm 1.22$ & $2.05 \pm 0.14$ & $24.81 \pm 5.17$ & $53.11 \pm 3.92$ \\
\hline
\end{tabular}

Table 2. Tai Chi quan affecting usea nitrogen, creatinine and creatinine scavenging rate.

\begin{tabular}{cccc}
\hline Time & Usea nitrogen $(\mathbf{m m o l} / \mathbf{L})$ & Creatinine $(\boldsymbol{\mu m o l} / \mathbf{L})$ & Creatinine scavenging rate $(\mathbf{m l} / \mathbf{m i n})$ \\
\hline 0 & $11.21 \pm 1.06$ & $274.54 \pm 84.72$ & $53.61 \pm 3.09$ \\
3 & $10.97 \pm 1.32$ & $256.71 \pm 93.32$ & $49.84 \pm 4.16$ \\
6 & $10.31 \pm 0.98$ & $247.41 \pm 89.67$ & $46.11 \pm 3.87$ \\
9 & $9.84 \pm 0.83$ & $221.48 \pm 92.53$ & $43.14 \pm 3.35$ \\
12 & $9.24 \pm 0.95$ & $214.63 \pm 100.57$ & $38.68 \pm 2.81$ \\
\hline
\end{tabular}

nephritis (swelling of the area between the renal tubules), Lupus Nephritis (A auto-immune disease factor leading to the inflammation) and Pyelonephritis (swelling due to the spread of a urinary infection to the kidney) (Hodgin et al., 2009). It has been reported by many researchers, that blood rheology plays an important role in the cases of diseases related to the cardiovascular system (Barbenel et al., 1983; Dormandy, 1987; Rezazadeh et al., 2009).

The main factors that affect blood's rheological behaviour, are whole blood viscosity, plasma viscosity, haematocrit, mechanical and physicochemical properties of erythrocytes (Lowe and Barbenel, 1988; Begg and Hearns, 1966; Marinakis, 1994). Significant changes in high-shear whole blood viscosity, low-shear whole blood viscosity, plasma viscosity, erythrocyte sedimentation rate (ESR), and hematocrit (HCT) were observed in the old people (Table 1). "Tai Chi" quan exercise significantly decreases these indexs in practicers. Moreover, the decrease was strengthen with prolonged practice time. These results indicated that improvement in blood rheology is useful for old people with nephritis.

The blood urea nitrogen (BUN, pronounced "B-U-N") test is a measure of the amount of nitrogen in the blood in the form of urea, and a measurement of renal function. Urea is a by- product from metabolism of proteins by the liver, and therefore removed from the blood by the kidneys (Chen et al., 2008; Yibchok-anun et al., 2009). Measuring serum creatinine is a useful and inexpensive method of evaluating renal dysfunction. Creatinine is a non-protein waste product of creatine phosphate metabolism by skeletal muscle tissue. Creatinine production is continuous and is proportional to muscle mass. Creatinine is freely filtered and therefore the serum creatinine level depends on the Glomerular Filtration Rate (GFR). Renal dysfunction diminishes the ability to filter creatinine and the serum creatinine rises. If the serum creatinine level doubles, the GFR is considered to have been halved. A threefold increase is considered to reflect a $75 \%$ loss of kidney function (Argirov et al., 2005).

Significant changes in Usea nitrogen, Creatinine and Creatinine scavenging rate were observed in the old people (Table 2). "Tai Chi" quan exercise significantly decreases these indexs in practicers. Moreover, the decrease was also strengthen with prolonged practice time. These results indicated that "Tai Chi" exercise could improve urinary disorders induced by nephritis.

\section{REFERENCES}

Argirov M, Ricken G, Zecher D, Fischereder M (2005). Acute interstitial nephritis associated with moxifloxacin use. Clin. Ther., 27: 12601263.

Barbenel JC, Lowe GDO, Forbes C (1983). The viscosity of blood, in "Mathematics in Medicine and Biomechanics". Ed. G Roach, Shira Publ, Nantwick.

Begg T, Hearns J (1966). Components in blood viscosity. Clin. Sci., 31: 87-93.

Bohannon RW, Larkin PA, Cook AC, Gear J, Singer J (1984). Decrease in timed balance test scores with aging, Phys. Ther., 64: 1067-1070.

Chen SM, Sato N, Yoshida M, Satoh N, Ueda S (2008). Effects of Bupleurum scorzoneraefolium, Bupleurum falcatum, and saponins on nephrotoxic serum nephritis in mice. J. Ethnopharmacol., 116: 397402.

Dooley MA, Falk RJ (2007). Human Clinical Trials in Lupus Nephritis. Seminars Nephrol., 27: 115-127.

Dormandy J (1987). Cardiovascular diseases, in "Clinical Hemorheology". Ed S Chien, J. Dormandy, E Ernst and A Matrai. Martinus Nijhoff Publishers. 
Hodgin JB, Whelan J, Markowitz GS, Barry SM (2009). Giant Cell Tubulitis with Immune Complex Deposits in a Patient with Lupus Nephritis. Am. J. Kidney Dis., 53: 513-517.

Hong Y, Li JX, Robinson PD (2000). Balance control, flexibility, and cardiorespiratory fitness among older Tai Chi practitioners, $\mathrm{Br}$. J. Sports Med., 34: 29-34.

Iverson BD, Gossman MR, Shaddeau SR, Turner ME (1990). Balance performance, force production, and activity levels in noninstitutionalized men 60-90 years of age, Phys. Ther., 70: 348-355.

Jonsson E, Seiger A, Hirschfeld H (2004). One-leg stance in healthy young and elderly adults: a measure of postural steadiness, Clin. Biomech., 19: 688-694.

Lamb EJ, O'Riordan SE, Delaney MP (2003). Kidney function in older people: pathology, assessment and management. Clin. Chim. Acta., 334: 25-40.

Lowe GDO, Barbenel JC (1988). Plasma and blood viscosity, in "Clinical Blood Rheology". Ed GDO Lowe, CRC Press Inc, Boca Raton, Florida.

Marinakis G (1994). The measurement and characterization of whole blood viscosity. MPhil thesis, University of Strathclyde, Glasgow.

Morteza E, Akbari GA, Sanavi SAMM, Farahani HA (2010). Determination of the vegetative and reproductive characteristics of valerian (Valeriana officinalis L.) under sowing dates and planting densities in Iran. J. Med. Plants Res., 4(10): 857-861.
Nkeh-Chungag BN, Temdie JR, Sewani-Rusike C, Fodjo YM, Mbafor JT, Iputo JE (2009). Analgesic, anti-inflammatory and antiulcer properties of the extract of Uapaca guineensis (Euphorbiaceae). J. Med. Plants Res., 3(9): 635-640.

Rezazadeh SH, Zaringhalam J, Manaheji H, Kebryaeezadeh A (2009). Anti-inflammatory and anti-hyperalgesic activities of Stachys athorecalyx extracts on CFA-induced inflammation. J. Med. Plants Res., 3(5): 368-376.

Schaller KJ (1996). Tai Chi Chih: an exercise option for older adults, J. Gerontol. Nurs., 22: 12-17.

Snedecor GW, Cochran WG (1989). Statistical methods (8th ed), The lowa State Univesity Press, Ames (lowa).

Swaim L, Fu ZW (1999). Mastering Yang style Taijiquan, North Atlantic, Berkeley, CA.

Yang CS, Lin CH, Chang SH, Hsu HC (2000). Rapidly progressive fibrosing interstitial nephritis associated with Chinese herbal drugs. Am. J. Kidney Dis., 35: 313-318.

Yang Z (1991). Yang style Taijiquan (2nd ed.), Morning Glory, Beijing.

Yibchok-anun S, Jittaprasatsin W, Somtir D, Bunlunara W, Adisakwattana S (2009). Insulin secreting and a-glucosidase inhibitory activity of Coscinium fenestratum and postprandial hyperglycemia in normal and diabetic rats. J. Med. Plants Res., 3(9): 646-651. 